\title{
Complete genome sequence and comparative genomics of the golden pompano (Trachinotus ovatus) pathogen, Vibrio harveyi strain QT520
}

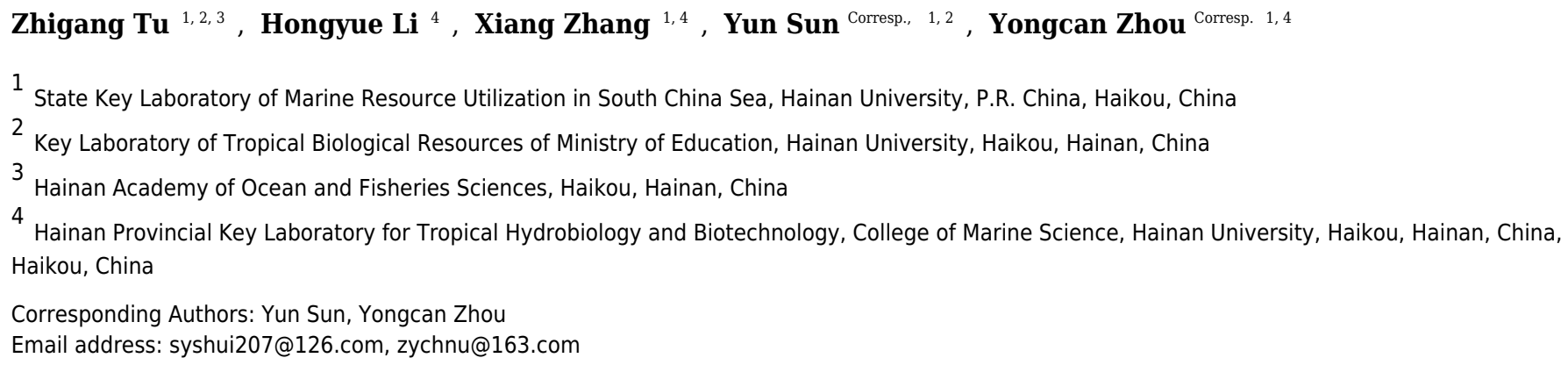

Vibrio harveyi is a Gram-negative, halophilic bacterium that is an opportunistic pathogen of commercially farmed marine vertebrate species. To understand the pathogenicity of this species, the genome of $V$. harveyi QT520 was analyzed and compared to that of other strains. The results showed the genome of QT520 has two unique circular chromosomes and three endogenous plasmids, totaling 6,070,846 bp with a 45\% GC content, 5701 predicted ORFs, 134 tRNAs and 37 rRNAs. Common virulence factors, including ACF, IlpA, OmpU, Flagellin, Cya, Hemolysin and MARTX, were detected in the genome, which are likely responsible for the virulence of QT520. The results of genomes comparisons with strains ATCC 33843 (392 [MAV]) and ATCC 43516 showed that greater numbers genes associated with types I, II, III, IV and VI secretion systems were detected in QT520 than in other strains, suggesting that QT520 is a highly virulent strain. In addition, three plasmids were only observed in the complete genome sequence of strain QT520. In plasmid p1 of QT520, specific virulence factors (cyaB, hlyB and rtxA) were identified, suggesting that the pathogenicity of this strain is plasmid-associated. Phylogenetic analysis of 12 complete Vibrio sp. genomes using ANI values, core genes and MLST revealed that QT520 was most closely related to ATCC 33843 (392 [MAV]) and ATCC 43516, suggesting that QT520 belongs to the species $V$. harveyi. This report is the first to describe the complete genome sequence of a $V$. harveyi strain isolated from an outbreak in a fish species in China. In addition, to the best of our knowledge, this report is the first to compare the $V$. harveyi genomes of several strains. The results of this study will expand our understanding of the genome, genetic characteristics, and virulence factors of $V$. harveyi, setting the stage for studies of pathogenesis, diagnostics, and disease prevention. 


\section{Complete Genome Sequence and Comparative Genomics of the Golden}

$6{ }^{1}$ State Key Laboratory of Marine Resource Utilization in South China Sea, Hainan University, 7 P.R. China

$8{ }^{2}$ Key Laboratory of Tropical Biological Resources of Ministry of Education, Hainan University,

9 Haikou, Hainan, 570228, China

$10{ }^{3}$ Hainan Academy of Ocean and Fisheries Sciences, Haikou, Hainan 571126, China

$11{ }^{4}$ Hainan Provincial Key Laboratory for Tropical Hydrobiology and Biotechnology, College of

12 Marine Science, Hainan University, Haikou, Hainan 570228, China

13 * To whom correspondence should be addressed

15 Mailing address:

College of Marine Sciences

Hainan University

Haikou 570228

21 Email: zychnu@163.com (Y.C.Zhou) 
28 ABSTRACT

29 Vibrio harveyi is a Gram-negative, halophilic bacterium that is an opportunistic pathogen of

30 commercially farmed marine vertebrate species. To understand the pathogenicity of this species,

31 the genome of $V$. harveyi QT520 was analyzed and compared to that of other strains. The results

32 showed the genome of QT520 has two unique circular chromosomes and three endogenous

33 plasmids, totaling 6,070,846 bp with a 45\% GC content, 5701 predicted ORFs, 134 tRNAs and

3437 rRNAs. Common virulence factors, including ACF, IlpA, OmpU, Flagellin, Cya, Hemolysin

35 and MARTX, were detected in the genome, which are likely responsible for the virulence of

36 QT520. The results of genomes comparisons with strains ATCC 33843 (392 [MAV]) and ATCC

3743516 showed that greater numbers genes associated with types I, II, III, IV and VI secretion

38 systems were detected in QT520 than in other strains, suggesting that QT520 is a

39 highly virulent strain. In addition, three plasmids were only observed in the complete genome

40 sequence of strain QT520. In plasmid p1 of QT520, specific virulence factors (cyaB, hlyB and

$41 \operatorname{rtx} A$ ) were identified, suggesting that the pathogenicity of this strain is plasmid-associated.

42 Phylogenetic analysis of 12 complete Vibrio sp. genomes using ANI values, core genes and

43 MLST revealed that QT520 was most closely related to ATCC 33843 (392 [MAV]) and ATCC

44 43516, suggesting that QT520 belongs to the species $V$. harveyi. This report is the first to

45 describe the complete genome sequence of a $V$. harveyi strain isolated from an outbreak in a fish

46 species in China. In addition, to the best of our knowledge, this report is the first to compare the

$47 \quad V$. harveyi genomes of several strains. The results of this study will expand our understanding of

48 the genome, genetic characteristics, and virulence factors of $V$. harveyi, setting the stage for

49 studies of pathogenesis, diagnostics, and disease prevention. 


\section{INTRODUCTION}

52 Vibrio harveyi ( . harveyi) is a Gram-negative, halophilic bacterium that is recognized as an

53 opportunistic pathogen of many commercially farmed marine invertebrate and vertebrate species

54 (Austin \& Zhang, 2006; Cano-Gomez, Owens \& Andreakis, 2011). V. harveyi is capable of

55 causing mass mortalities in aquaculture settings and has a major impact on the industry. Species

56 affected throughout the world include the gilthead sea bream (Sparus aurata), European sea bass

57 (Dicentrarchus labrax), common dentex (Dentex dentex), Senegalese sole (Solea senegalensis)

58 and prawn (Penaeus monodon) (Austin \& Zhang, 2006; Chabrillón et al., 2005; Lavillapitogo et

59 al., 1990; Pujalte et al., 2003; Won \& Park, 2008; Zorrilla et al., 2003). V. harveyi was also

60 reported to infect many aquaculture species in China and is now considered as one of the major

61 pathogens in the fisheries industry (Cui et al., 2014; Chen et al., 2004; Li \& Xu, 1998; Zhang et

62 al., 2010).

63 Many studies have reported on the pathogenic mechanisms of $V$. harveyi, and variability in

64 virulence mechanisms were found to be strain dependent toward different host species (Austin \&

65 Zhang, 2006; Bai et al., 2008; Zhang \& Austin, 2000). Some reports have shown that

66 extracellular products (ECPs) including proteases, phospholipases, hemolysins and cytotoxins,

67 play significant roles in the pathogenicity of $V$. harveyi (Liu \& Lee, 1999; Liuxy, Lee \& Chen,

68 1996; Zhang \& Austin, 2000). However, in fatal cases in Artemia franciscana nauplii and some

69 cultured marine fishes, the hemolytic activity of $V$. harveyi was not a significant factor (Soto-

70 Rodriguez et al., 2003; Won \& Park, 2008). Siderophore production has been strongly correlated

71 with fish mortality, and it is considered to be an essential virulence factor in some bacterial 
72 species (Ratledge \& Dover, 2003), but the effect is less obvious in others (Pedersen et al., 1997).

73 In recent years, Type III secretion systems (TTSS), bacteriophages, and quorum-sensing

74 mechanisms, which play important roles in effector translocation, conversion of virulence factors,

75 and regulation of virulence gene expression, respectively, have all been shown to be associated

76 with virulence (Henke \& Bassler, 2004; Natrah et al., 2011; Ruwandeepika et al., 2012). To

77 further understand the pathogenesis and the associated virulence factors of $V$. harveyi, the

78 determination of the genomic information of various $V$. harveyi strains is crucial.

79 In this study, we isolated a $V$. harveyi from a diseased golden pompano (Trachinotus ovatus)

80 cultured in a deep sea cage in Qiaotou, China and named it QT520. Genome and comparative

81 genome analyses were used in the current study to analyze the pathogenesis of $V$. harveyi. The

82 results will help to characterize pathogenesis, diagnostics, and disease prevention.

\section{MATERIALS AND METHODS}

\section{Ethics statement}

87 All protocols for experiments involving live animals conducted in this study were approved by

88 the Animal Experimental Inspection of Laboratory Animal Centre, Hainan University (Haikou,

89 China), and the approval number is 20160709 . And we conscientiously abided by the ethical

90 principles of animal welfare and the rule of laboratory animal center.

\section{Bacterial Strain Isolation}


94 signs of body rot. To obtain a pure culture, a single colony of strain QT520 was selected and

95 transferred to fresh TCBS medium at least three times. Then, the clone was cultivated at $30^{\circ} \mathrm{C}$ in

96 2216E liquid medium for $16 \mathrm{~h}$. The cell morphology of QT520 and contamination of the culture

97 with other microorganisms were assessed by light microscopy (BA410; Motic, China). The strain

98 was archived at Hainan University and Hainan Academy of Ocean and Fisheries Sciences under

99 accession number QT520.

100

101 Genomic DNA Extraction and Whole Genome Sequencing

102 Genomic DNA was extracted using a Rapid Bacterial Genomic DNA Isolation Kit (Sangon

103 Biotech, Shanghai) according to the manufacturer's instructions. The concentration and purity of

104 the extracted DNA were determined using a DNA Qubit 2.0 (Invitrogen, Carlsbad, CA, USA).

105 The extracted genomic DNA was used to construct next-generation libraries with an insert size of

106500 bp using a NEBNext ${ }^{\circledR}$ Ultra $^{\mathrm{TM}}$ DNA Library Prep Kit for Illumina ${ }^{\circledR}$ and PacBio RS II

107 libraries with an insert size of $10 \mathrm{~kb}$.

108 Genome sequencing was conducted by Sangon Biotech Co., Ltd. (Shanghai, China) using the 109 next-generation Illumina MiSeq (Illumina, San Diego, CA, USA) and the third-generation

110 PacBio RS II sequencing platform (Pacific Biosciences, Menlo Park, CA, USA), respectively.

111 The raw sequences obtained from the third-generation PacBio RS II sequencing platform were

112 assembled using Canu (Koren et al., 2016). Gapcloser and GapFiller were used to close the gaps

113 with next-generation sequence reads where possible after assembly (Boetzer \& Pirovano, 2012)

114 and the sequence variants were detected and assembled by PrInSeS-G to obtain high115 quality, whole-genome sequences (Massouras et al., 2010). 


\section{Genome Analysis}

118 Prokka was used to predict and annotate prokaryotic ORFs, tRNAs and rRNAs (Seemann,

119 2014). Clusters of Orthologous Groups (COG) analysis was performed using RPS BLAST.

120 Antibiotic resistance genes and genes encoding virulence factors were identified through BLAST

121 searches of the Comprehensive Antibiotic Resistance Database (CARD) and the Virulence

122 Factors of Pathogenic Bacteria Database (VFDB), respectively. Circular genome maps were

123 generated using the CGView Server (Grant \& Stothard, 2008) based on the information

124 generated by the genome annotation.

\section{Phylogenetic Analyses}

127 Four phylogenetic trees were constructed based on average nucleotide identity (ANI), core

128 genes, multilocus sequence typing (MLST), and the 16S rRNA gene, respectively. The ANI

129 values were calculated using Jspecies (Goris et al., 2007) and phylogenetic tree analysis of 12

130 available complete genome sequences of Vibrio sp. strains (Supplementary Table 1) based on

131 ANI values was performed using the R package Ape with neighbor-joining methods ( $\underline{\text { Paradis et }}$

132 al., 2004). The core genes of the 12 genomes were obtained using cd-hit 4.6.1, the corresponding

133 protein sequences were aligned using MUSCLE 3.8.31 and the phylogenetic trees were generated

134 using Treebest 1.9.2 (Caputo et al., 2015; Mbengue et al., 2016). Four different housekeeping

135 genes were used to construct the MLST phylogenetic tree: toxR, vhhA, ompK and hsp60. The 16S

136 rRNA gene sequences and the corresponding amino acid sequences inferred from the four genes

137 for MLST were respectively aligned with those of the most closely related species using the 
138 multiple alignment program ClustalW. Phylogenetic relationships between strain QT520 and

139 closely related species were determined using the MEGA6 software. Phylogenetic trees were

140 generated using the neighbor-joining (NJ) method with 1,000 randomly selected bootstrap

141 replicates.

142

143 Comparative Genomics

144 Genomes of ATCC 33843 (392 [MAV]), ATCC 43516, and QT520 were compared through

145 Mauve using the default parameters (Darling et al., 2004; Mbengue et al., 2015). The locations of

146 different genes in the gene clusters were visualized using SVG 1.1, and ImageMagick 6.5.4-7

147 was used to convert SVG format to PNG.

148

149 Determination of Median Lethal Dose (LD50)

150 The isolated QT520 strain was inoculated into 2216E liquid medium and incubated on a

151 shaker $(180 \mathrm{rpm})$ at $30^{\circ} \mathrm{C}$ overnight, after which a culture containing $1.47 \times 10^{8} \mathrm{CFU} / \mathrm{mL}$ obtained.

152 During challenge, the bacterial suspension was serially diluted 10-fold using Stroke-

153 Physiological Saline Solution and was used to infect T. ovatus (10 fish/group) by intraperitoneal

154 injection with $1.47 \times 10^{8} \mathrm{CFU} / \mathrm{mL}, 1.47 \times 10^{7} \mathrm{CFU} / \mathrm{mL}, 1.47 \times 10^{6} \mathrm{CFU} / \mathrm{mL}$ or $1.47 \times 10^{5} \mathrm{CFU} / \mathrm{mL}$.

155 The control group was injected with Stroke-Physiological Saline Solution. Fish deaths were

156 recorded for 2 weeks and the Reed-Muench method was used to calculate the median lethal

157 dosage.

158

159 RESULTS 
160 General Features of V. harveyi QT520

161 Through the use of a combination of sequencing approaches using the MiSeq and PacBio

162 platforms, we were able to assemble five contigs with $227.76 \times$ coverage. The genome sequence

163 of strain QT520 was deposited in the DDBJ/EMBL/GenBank under the accession numbers

164 CP018680-CP018684. The project information, according to the minimum information about a

165 genome sequence (MIGS) recommendation (Field et al., 2008), is shown in Supplementary Table

166 2. The strain QT520, which was isolated from cultured T. ovatus exhibiting clinical signs of body

167 rot, was Gram-negative and aerobic. After negative staining it was observed to be an oval, rod-

168 shaped cell approximately 1.6-2.2 $\mu \mathrm{m}$ in length and 1.0-1.1 $\mu \mathrm{m}$ in width with a single polar

169 flagellum (Fig. 1).

170

[Fig. 1]

171

\section{Genomic Information}

173 The QT520 genome was a total of $6070846 \mathrm{bp}$, consisting of two circular chromosomes and

174 three circular plasmids (chromosome I, 3560044 bp; chromosome II, 2260627 bp; plasmid p1,

175113574 bp; plasmid p2, 76744 bp; plasmid p3, 59857 bp) (Fig. 2). The genome had an overall

$176 \mathrm{G}+\mathrm{C}$ content of $45 \%$ (Table 1). A total of 3377 open reading frames (ORFs) were detected in

177 Chromosome I, including 3195 coding sequences (CDSs), 118 tRNA genes, 34 rRNA genes, 29

178 miscRNA and 1 tmRNA; $2425 \mathrm{CDSs}$ (75.90\% of $3195 \mathrm{CDSs}$ ) were annotated as functional

179 genes, and 770 CDSs (24.10\%) were annotated as hypothetical or uncharacterized genes.

180 Chromosome II contained 2061 ORFs, 2030 CDSs, 16 tRNA genes, 3 rRNA genes and 12

181 miscRNA; 1476 CDSs (72.71\%) were annotated as functional genes, and 554 CDSs (27.29\%) 
182 were annotated as hypothetical or uncharacterized genes. The chromosome maps (Fig. 3) display

1833657 ORFs (64.15\% of the total number of predicted ORFs) that encode known functional

184 proteins, and 423 ORFs having no known function in our COG functional categorization. Among

185 the functionally predicted ORFs, 2593 ORFs (63.55\% of the COG-assigned ORFs) belonged to

186 nine major COG functional categories: 527 ORFs in category R (General function prediction

187 only), 329 ORFs in category K (Transcription), 287 ORFs in category E (Amino acid transport

188 and metabolism), 276 ORFs in category $\mathrm{T}$ (Signal transduction mechanisms), 254 ORFs in

189 category G (Carbohydrate transport and metabolism), 241 ORFs in category C (Energy

190 production and conversion), 243 ORFs in category P (Inorganic ion transport and metabolism),

191236 ORFs in category M (Cell wall/membrane/envelope biogenesis) and 200 ORFs in category J

192 (Translation, ribosomal structure and biogenesis).

[Table 1] [Fig. 2] [Fig. 3]

\section{Virulence Factors of $V$. harveyi QT520}

196 Virulence factors of strain QT520 are listed in Supplementary Table 3. The results of the

197 QT520 genome analysis revealed a number of common virulence determinants, such as ACF,

198 IlpA, OmpU, Flagella, T6SS, TTSS, Cya, Hemolysin and MARTX. Factors responsible for iron

199 acquisition, including IutA, Chu, Enterobactin, FeoAB and Mycobactin were also present. In

200 addition, some adhesion proteins (Capsule/CapsuleI, Los, IlpA, MAM7 and OmpU),

201 antiphagocytosis proteins (Alginate), efflux pumps, endotoxins, and stress proteins were also

202 found in strain QT520.

203 Phylogenetic Analysis 
204 Four comparative phylogenetic tree analysis methods were used to identify closely related

205 strains of QT520: ANI, core genes, MLST, and 16S rRNA gene sequencing. For phylogenetic

206 tree analysis using ANI, 11 complete genome sequences available in the NCBI GenBank

207 database, as well as that of QT520, were obtained and the ANI values were calculated

208 (Supplementary Table 4). A phylogenetic tree based on ANI values was constructed (Fig. 4A).

209 The tree identified a subgroup that contained 1114GL, LMB29, ATCC BAA-1116, ATCC 33843

210 (392 [MAV]), ATCC 43516 and QT520, which was designated Group I. Within this group, the

211 genome of QT520 was most closely related to those of ATCC 33843 (392 [MAV]) and ATCC

21243516 (98.49 and 98.59\% of ANI values, respectively).

213 An additional phylogenetic tree of the 12 complete genome sequences described above was

214 constructed using the core genes method (Fig. 4B). The results showed that ATCC 33843 (392

215 [MAV]) and ATCC 43516 were the closest in Group I and that QT520 was closely related to both

216 strains, supporting that the ANI and core genes methods could distinguish them even at the strain

217 level.

218 Another phylogenetic tree was generated using MLST with four different housekeeping

219 genes: toxR, $v h h A, \operatorname{ompK}$ and $h s p 60$. The DNA sequences of the four MLST genes in the Group I

220 strains were compared and aligned to generate a phylogenetic tree (Fig. 4C). The results showed

221 that the genomes of QT520, ATCC 33843 (392 [MAV]) and ATCC 43516 were again the closest

222 relatives and those of 1114GL, LMB29 and ATCCBAA-1116 were the closest in Group I.

223 However, comparative phylogenetic tree analysis using 16S rRNA sequences of the Group I

224 strains revealed that strains QT520, 1114GL, ATCC 33843392 MAV and ATCC 43516 were the

225 closest relatives, being classified into one phylogenetic branch (Fig. 4D). 


\section{Comparative Genomics of $V$. harveyi ATCC 3843 (392 [MAV]) and ATCC 43516}

229 Comparative genomic analyses were conducted to compare $V$. harveyi QT520 with its most

230 closely related strains, V. harveyi ATCC 3843 (392 [MAV]) and ATCC 43516 (Fig. 5A). The

231 results showed that the number of core genes among the three strains is 4463 . The number of 232 specific genes in QT520, ATCC 3843, and ATCC 43516 are 458, 277 and 448, respectively.

233 Two genes (APP0488.1 and APP06774.1) identified as core genes encode a multi234 antimicrobial extrusion efflux family protein and a xanthine-guanine phosphoribosyltransferase, 235 respectively. The results suggested that the three $V$. harveyi strains may have multiple antibiotic 236 resistances to tigecycline, tetracycline, streptomycin, kanamycin, ciprofloxacin and norfloxacin 237 (Kim et al., 2003; Kuroda \& Tsuchiya, 2009; Teo et al., 2002).

238 Virulence factor genes, including APP05600.1, APP06379.1, APP06380.1, APP06382.1, 239 APP6383.1, APP06387.1, APP06388.1, APP07902.1, APP09130.1, APP09132.1, APP09134.1,

240 APP09207.1 and APP09259.1 were only observed in strain QT520 based on the comparative 241 analysis results (Supplementary Table 3 and Fig. 5A). These specific genes encode Type IV pili,

242 O-antigen, LPS, Capsule, Cya, hemolysin, MARTX and TTSS (SPI-1), respectively. These genes 243 are well known to play important roles in attachment, expression of other virulence factors, 244 preventing phagocytosis, anti-inflammatory effects, hemolytic activities and a cytotoxicity 245 (Ruwandeepika et al., 2012; Zhang \& Austin, 2000), suggesting that they may be responsible for 246 the virulence associated with the QT520 strain.

247 Genes associated with type I secretion systems (T1SS) and type VI secretion systems 
248 (T6SS) were detected in QT520, but not in ATCC 33843 (392 [MAV]) and ATCC 43516. The

249 numbers of type II, III and IV secretion systems (T2SS, T3SS, and T4SS) related genes in QT520

250 was 28, 32, and 21, respectively; the numbers of T2SS, T3SS, and T4SS related genes in ATCC

25133843 (392 [MAV]) was 7, 12, and 4, respectively. The numbers of genes T2SS, T3SS, and T4SS

252 related genes in ATCC 43516 was 7, 14, and 4, respectively. Greater numbers of genes associated

253 with the T1SS, T2SS, T3SS, T4SS and T6SS were detected in the genome sequence of QT520

254 than in strains ATCC 33843 (392 [MAV]) and ATCC 43516 (Table 2 and Fig. 5). In addition,

255 T1SS were detected in regions of chromosome I (APP04465.1), chromosome II (APP08059.1

256 and APP08730.1) and plasmid p1 (APP09130.1 and APP09132.1) of QT520. T2SS and T3SS

257 were detected in the regions APP04623.1-APP08089.1 and APP04087.1-APP08428.1 in

258 chromosomes I and II, respectively. Nine T4SS-encoding genes were detected in the insertion

259 region in QT520 compared to ATCC 3843(392[MAV]) and ATCC 43516 (Fig. 5B and Fig. 5C),

260 and other T4SS-encoding genes were primarily distributed in regions of chromosome I

261 (APP05190.1-APP05200.1) and chromosome II (APP07457.1 to APP08116.1). T6SS-related

262 genes were detected in regions of chromosome I (APP04433.1 to APP4446.1) and chromosome II

263 (APP07649.1 to APP07972.1).

264

[Table 2]

265

266 Three plasmids were detected in $V$. harveyi strain QT520 that were not observed in strains

267 ATCC 3843(392[MAV]) and ATCC 43516. In particular, three important virulence factor genes

$268(c y a B, h l y B$ and $r t x A)$ were present in plasmid $\mathrm{p} 1$.

269

[Fig. 5] 
271

272

273

274

275

276

277

278

279

280

281

282

283

284

285

286

287

288

289

290

291

\section{$\mathbf{L D}_{50}$}

Artificial infection results showed that the $\mathrm{LD}_{50}$ of QT520 was $2.5 \times 10^{5}$ bacteria per fish, suggesting that this bacterium is strongly pathogenicity to T. ovatus (Table 3).

\section{[Table 3]}

\section{DISCUSSION}

Since species within the Harveyi clade have a high degree of genetic and phenotypic similarity (Sawabe et al., 2007), identification of $V$. harveyi strains is a challenging task. For example, the species $V$. harveyi, $V$. campbellii and $V$. rotiferianus share approximately $99 \%$ sequence identity within the 16S rRNA gene (Gomez-Gil, 2003). These similarities have confounded typing schemes and resulted in documented misidentifications (Gauger \& Gomezchiarri, 2002; Gomezgil et al., 2004). Recently, novel phylogenetic analysis approaches have been suggested, specifically, ANI, core genes and MLST. The ANI and core genes method was performed using the 12 complete genome sequences available for Vibrio sp. In this study, the analysis based on core genes and MLST revealed that QT520, ATCC 3843(392[MAV]) and ATCC 43516 were the most closely related and that 1114GL, LMB29 and ATCCBAA-1116 were the closest in Group I, which was consistent with the analysis using ANI values. However, these strains could not be differentiated using the $16 \mathrm{~S}$ rRNA phylogenetic tree, suggesting that ANI, core genes and MLST methods can provide a greater level of resolution between $V$. harveyi and V. campbellii compared to the $16 \mathrm{~S}$ rRNA method. The pathogenicity of $V$. harveyi strains is related to a number of factors, including secretion 
292 of ECPs (containing substances such as proteases, hemolysins, and lipases) (Teo et al., 2003;

293 Zhang \& Austin, 2000), a bacteriocin-like substance (Prasad et al., 2005), quorum sensing

294 capabilities (Henke \& Bassler, 2004), susceptibility to bacteriophage infection (Oakey \& Owens,

295 2000) and siderophore production (Owens, Austin \& Austin, 1996). The observed LD $_{50}$ of QT520

296 was $2.5 \times 10^{5}$ bacteria per fish, suggesting that this bacterium is a highly virulent strain towards $T$.

297 ovatus. Various virulence factor genes, including ACF, IlpA, MAM7, OmpU, Type IV pili,

298 Flagellin, Cya, Hemolysin and MARTX, were observed in this strain. These genes may be

299 responsible for the high virulence associated with the QT520 strain.

300 The ability of pathogens to obtain iron from their host is central to their survival (Ratledge \&

301 Dover, 2003). The genome of the QT520 strain encodes the aerobactin siderophore receptor

302 (detected at the APP07707.1 region on chromosome II), heme receptors (at the region

303 APP04364.1 on chromosome I and the region APP07339.1 on chromosome II), and iron ABC

304 transport (APP03856.1-03858.1 and APP03907.1 on chromosome I). These iron uptake related-

305 genes may play key roles in the survival of the QT520 strain in host cells.

306 Secretion systems can transport various virulence factors outside of the bacterial cell and

307 allow bacteria to communicate within the environment in which they live. Greater numbers of

308 genes encoding T1SS, T2SS, T3SS and T4SS and T6SS components were found in strain QT520

309 than in strains ATCC 33843 (392 [MAV]) and ATCC 43516. Interestingly, the T1SS and T6SS

310 were only found in QT520. The T1SS is employed for secreting proteins, includes many

311 adhesins, proteases, and toxins that are delivered into host cells, and can secrete hemolysin in the

312 E. coli (Dalbey \& Kuhn, 2012). The T2SS is required for secretion of exotoxins, including the

313 cholera toxin (Ctx) (Abendroth, Kreger \& Hol, 2009). The T3SS, which is found in various 
314 pathogenic Gram-negative bacterial genera, such as Salmonella, Shigella, Yersinia,

315 Pseudomonas, and enteropathogenic Escherichia coli (EPEC) (Galan \& Wolf-Watz, 2006), serve

316 several well defined functions in pathogenesis. The T4SS is responsible for the transport of

317 virulent proteins or DNA into eukaryotic cells as well as for the conjugative transfer of plasmids

318 from one bacterium to another (Fronzes et al., 2009) and were found in the insertion regions,

319 suggesting that the T4SS may play important roles in the pathogenicity of QT520. The T6SS,

320 which is associated with cytotoxic effectors (Costa et al. 2015; Unterweger et al., 2014),

321 translocates toxic effector proteins into eukaryotic and prokaryotic cells and has a pivotal role in

322 pathogenesis and bacterial competition (Ho et al. 2014; Zoued et al., 2014), and this system was

323 also reported in the pathogenic Vibrio harveyi strains ZJ0603 and CAIM 1792 (Huang et al.,

324 2012; Espinozavalles et al., 2012). This secretion system functions as a group of toxin proteins

325 by transporting various bacterial effectors into eukaryotic cells, resulting in host cell death (Costa

326 et al., 2015), and its presence suggests that QT520 is a highly virulent strain based on our

327 genome analysis. However, further analysis of the mechanisms of these secretion systems in $V$.

328 harveyi is required.

329 Interestingly, we observed three plasmids in the complete genome sequence of strain

330 QT520, which have not been identified in strains ATCC 33843 (392 [MAV]) and ATCC 43516.

331 Through comparative genomic analysis, three specific virulence factors (Cya, Hemolysin and

332 RTX toxin), encoded by $c y a B, h l y B$ and $r t x A$, were observed in plasmid p1 of strain QT520,

333 suggesting that the pathogenicity of this strain is closely related to plasmid $\mathrm{p} 1$. Studies have also

334 reported that a plasmid, pVCR1, was harbored by the highly virulent $V$. harveyi ORM4 strain,

335 suggesting its involvement in the virulence phenotype (Schikorski et al., 2013). The virulence of 
$336 V$. harveyi was believed to be acquired by association with genetically mobile elements, such as

337 plasmids or transposons (Austin \& Zhang, 2006). Non-virulent $V$. harveyi strains can become

338 virulent after plasmid uptake or bacteriophage-mediated transfer of toxin gene(s) (Oakey \&

339 Owens, 2000). Thus, we inferred that the pathogenicity of QT520 has been acquired by the

340 incorporation of plasmids.

341 Through comparative analyses of the complete genomes of the three $V$. harveyi strains, a

342 majority of the genes analyzed were observed to be core genes, including the antibiotic resistance

343 genes reported previously in the complete genome sequences of $V$. harveyi ATCC 3843

344 (392[MAV]) and ATCC 43516. This suggests that the three $V$. harveyi strains likely possess

345 similar antibiotic resistances to tigecycline, tetracycline, streptomycin, kanamycin, ciprofloxacin

346 and norfloxacin. In addition, QT520 exhibited resistance against tetracycline, streptomycin and

347 kanamycin.

349 CONCLUSIONS

$350 \quad V$. harveyi, an opportunistic pathogen of many maricultured animals, can cause mass

351 mortalities in aquaculture species, posing a considerable threat to the industry. V. harveyi QT520,

352 which was isolated from diseased deep sea cage-cultured golden pompano, was observed to be a

353 virulent isolate with an LD50 of $2.5 \times 10^{5}$ bacteria per fish. To understand its pathogenesis, the

354 genome of $V$. harveyi QT520 was sequenced. This genome was observed to consist of two

355 circular chromosomes and three plasmids, totaling $6,070,846$ bp with a $45 \%$ GC content, as well

356 as containing 5701 predicted ORFs, 134 tRNAs and 37 rRNAs.

357 Phylogenetic analysis of 12 complete genomes of Vibrio sp. using ANI values and core 
358 genes revealed that QT520 was most closely related to ATCC 33843 (392 [MAV]) and ATCC

35943516 , indicating that QT520 belongs to the species $V$. harveyi.

360 Common virulence factors, including ACF, IlpA, OmpU, Flagellin, Cya, Hemolysin and

361 MARTX, were detected. These factors may be responsible for the virulence associated with

362 colonization by QT520. Additionally, greater numbers of genes encoding types I, II, III, IV and

363 VI secretion systems were detected in the genome of QT520 than in strains ATCC 33843 (392

364 [MAV]) and ATCC 43516, suggesting that strain QT520 has the capacity for a highly virulent

365 phenotype. It is worth mentioning that three specific virulence factor genes ( $c y a B, h l y B$ and $r \operatorname{tx} A$ )

366 were contained in plasmid $\mathrm{p} 1$ in this strain, suggesting that the pathogenicity of this strain is

367 plasmid associated. Comparative genome analysis of QT520, ATCC 33843 (392 [MAV]) and

368 ATCC 43516 revealed that the majority of ORFs were core genes, including two antibiotic

369 encoding genes, suggesting these strains are resistant to multiple antibiotics.

\section{REFERENCES}

372

373

374

375

376

377

378

379

380

381

382

383

384

385

386
Abendroth J, Kreger AC, and Hol WGJ. 2009. The dimer formed by the periplasmic domain of EpsL from the Type 2 Secretion System of Vibrio parahaemolyticus. Journal of Structural Biology 168:313-322. DOI: 10.1016/j.jsb.2009.07.022.

Austin B, and Zhang XH. 2006. Vibrio harveyi: a significant pathogen of marine vertebrates and invertebrates. Letters in Applied Microbiology 43:119-124. DOI: 10.1111/j.1472765X.2006.01989.x.

Bai F, Pang L, Qi Z, Chen J, Austin B, and Zhang X. 2008. Distribution of five vibrio virulencerelated genes among Vibrio harveyi isolates. Journal of General and Applied Microbiology 54:71-78. DOI: 10.2323/jgam.54.71.

Boetzer M, and Pirovano W. 2012. Toward almost closed genomes with GapFiller. Genome Biology 13:1-9. DOI: 10.1186/gb-2012-13-6-r56.

Cano-Gomez A, Høj L, Owens L, and Andreakis N. 2011. Multilocus sequence analysis provides basis for fast and reliable identification of Vibrio harveyi-related species and reveals previous misidentification of important marine pathogens. Systematic and Applied Microbiology 34:561-565. DOI: 10.1016/j.syapm.2011.09.001. 
387

388

389

390

391

392

393

394

395

396

397

398

399

400

401

402

403

404

405

406

407

408

409

410

411

412

413

414

415

416

417

418

419

420

421

422

423

424

425

426

427

428

429
Caputo A, Merhej V, Georgiades K, Fournier PE, Croce O, Robert C, and Raoult D. 2015. Pangenomic analysis to redefine species and subspecies based on quantum discontinuous variation: the Klebsiella paradigm. Biology Direct 10:55-55. DOI:10.1186/s13062-0150085-2.

Chabrillón M, Rico RM, Arijo S, Díaz-Rosales P, Balebona MC, and Moriñigo MA. 2005. Interactions of microorganisms isolated from gilthead sea bream, Sparus aurata L., on Vibrio harveyi, a pathogen of farmed Senegalese sole, Solea senegalensis (Kaup). Journal of Fish Diseases 28:531-537. DOI: 10.1111/j.1365-2761.2005.00657.x.

Chen X, Wu S, Shi C, and Li N. 2004. Isolation and identification of pathogenetic Vibrio harveyi from estuary cod Epinephelus coioides. Journal of Fishery Sciences of China 11:313-317. (In Chinese with English abstract)

Costa TRD, Felisberto-Rodrigues C, Meir A, Prevost MS, Redzej A, Trokter M, and Waksman G. 2015. Secretion systems in Gram-negative bacteria: structural and mechanistic insights. Nature Reviews Microbiology 13:343. DOI: 10.1038/nrmicro3456.

Cui J, Fan XT, Liu WZ, Li HY, Zhou YC, Wang SF, and Xie ZY. 2014. Isolation and Identification of Vibriosis Pathogens of Marine Culture Fishes in Southern China. Natural Science Journal of Hainan University 32:245-251. DOI: 10.15886/j.cnki.hdxbzkb.2014.03.013.

Dalbey RE, and Kuhn A. 2012. Protein traffic in Gram-negative bacteria--how exported and secreted proteins find their way. FEMS Microbiology Reviews 36:1023-1045. DOI: 10.1111/j.1574-6976.2012.00327.x.

Darling AE, Mau B, Blattner FR, and Perna NT. 2004. Mauve: Multiple Alignment of Conserved Genomic Sequence With Rearrangements. Genome Research 14:1394-1403. DOI: $10.1101 /$ gr.2289704.

Espinozavalles I, Sotorodriguez S, Edwards RA, Wang Z, Vora GJ, and Gomezgil B. 2012. Draft genome sequence of the shrimp pathogen Vibrio harveyi CAIM 1792. Journal of Bacteriology 194:2104-2104. DOI: 10.1128/JB.00079-12.

Fan W, Huang J, Wang X, Shi C, and Liu L. 2005. Identification and phylogenetic study of pathogenic bacteria causing ulcer disease of cultured Turbot (Scophthalmus maximus). Acta Microbiologica Sinica 45:665-670. (In Chinese with English abstract)

Field D, Garrity G, Gray T, Morrison N, Selengut J, Sterk P, Tatusova T, Thomson N, Allen MJ, Angiuoli SV, Ashburner M, Axelrod N, Baldauf S, Ballard S, Boore J, Cochrane G, Cole J, Dawyndt P, De Vos P, dePamphilis C, Edwards R, Faruque N, Feldman R, Gilbert J, Gilna P, Glockner FO, Goldstein P, Guralnick R, Haft D, Hancock D, Hermjakob H, Hertz-Fowler C, Hugenholtz P, Joint I, Kagan L, Kane M, Kennedy J, Kowalchuk G, Kottmann R, Kolker E, Kravitz S, Kyrpides N, Leebens-Mack J, Lewis SE, Li K, Lister AL, Lord P, Maltsev N, Markowitz V, Martiny J, Methe B, Mizrachi I, Moxon R, Nelson K, Parkhill J, Proctor L, White O, Sansone S-A, Spiers A, Stevens R, Swift P, Taylor C, Tateno Y, Tett A, Turner S, Ussery D, Vaughan B, Ward N, Whetzel T, San Gil I, Wilson $\mathrm{G}$, and Wipat A. 2008. The minimum information about a genome sequence (MIGS) specification. Nature Biotechnology 26:541-547. DOI: 10.1038/nbt1360.

Fronzes R, Christie PJ, and Waksman G. 2009. The structural biology of type IV secretion systems. Nature Reviews Microbiology 7:703-714. DOI: 10.1038/nrmicro2218. 
430

431

432

433

434

435

436

437

438

439

440

441

442

443

444

445

446

447

448

449

450

451

452

453

454

455

456

457

458

459

460

461

462

463

464

465

466

467

468

469

470

471

472

Galan, J. E. \& Wolf-Watz, H. 2006. Protein delivery into eukaryotic cells by type III secretion machines. Nature 444:567-573. DOI:10.1038/nature05272.

Gauger EJ, and Gomezchiarri M. 2002. 16S ribosomal DNA sequencing confirms the synonymy of Vibrio harveyi and $V$. carchariae. Diseases of Aquatic Organisms 52:39-46. DOI:10.3354/dao052039.

Gomez-Gil B. 2003. Vibrio rotiferianus sp. nov., isolated from cultures of the rotifer Brachionus plicatilis. International Journal of Systematic and Evolutionary Microbiology 53:239-243. DOI: 10.1099/ijs.0.02430-0.

Gomez-Gil B, Sotorodriguez S, Garciagasca A, Roque A, Vazquezjuarez R, Thompson FL, and Swings J. 2004. Molecular identification of Vibrio harveyi-related isolates associated with diseased aquatic organisms. Microbiology 150:1769-1777. DOI: 10.1099/mic.0.26797-0.

Grant JR, and Stothard P. 2008. The CGView Server: a comparative genomics tool for circular genomes. Nucleic Acids Research 36:W181-184. DOI 10.1093/nar/gkn179.

Goris J, Konstantinidis KT, Klappenbach JA, Coenye T, Vandamme P, and Tiedje JM. 2007. DNA-DNA hybridization values and their relationship to whole-genome sequence similarities. International Journal of Systematic and Evolutionary Microbiology 57:81-91. DOI: 10.1099/ijs.0.64483-0.

Henke JM, and Bassler BL. 2004. Quorum sensing regulates type III secretion in Vibrio harveyi and Vibrio parahaemolyticus. Journal of Bacteriology 186:3794-3805. DOI: 10.1128/JB.186.12.3794-3805.2004.

Ho BT, Dong TG, and Mekalanos JJ. 2014. A View to a Kill: The Bacterial Type VI Secretion System. Cell Host \& Microbe 15:9-21. DOI: 10.1016/j.chom.2013.11.008.

Huang Y, Jian J, Lu Y, Cai S, Wang B, Tang J, Pang H, Ding Y, and Wu Z. 2012. Draft Genome Sequence of the Fish Pathogen Vibrio harveyi Strain ZJ0603. Journal of Bacteriology 194:6644-6645. DOI: 10.1128/jb.01759-12.

Kim S, Nonaka L, Oh M, Lavillapitogo CR, and Suzuki S. 2003. Distribution of an Oxytetracycline Resistance Determinant tet(34) among Marine Bacterial Isolates of a Vibrio species. Microbes and Environments 18:74-81. DOI: 10.1264/jsme2.18.74.

Konstantinidis KT, and Tiedje JM. 2007. Prokaryotic taxonomy and phylogeny in the genomic era: advancements and challenges ahead. Current Opinion in Microbiology 10:504-509. DOI: 10.1016/j.mib.2007.08.006.

Koren S, Walenz BP, Berlin K, Miller JR, and Phillippy AM. 2016. Canu: scalable and accurate long-read assembly via adaptive k-mer weighting and repeat separation. DOI: 10.1101/gr.215087.116.

Kuroda T, and Tsuchiya T. 2009. Multidrug efflux transporters in the MATE family. Biochimica et Biophysica Acta (BBA) - Proteins and Proteomics 1794:763-768. DOI: 10.1016/j.bbapap.2008.11.012.

Lavillapitogo CR, Baticados MCL, Cruzlacierda ER, and La Pena LDD. 1990. Occurrence of luminous bacterial disease of Penaeus monodon larvae in the Philippines. Aquaculture 91:1-13. DOI: 10.1016/0044-8486(90)90173-K.

Li J, and Xu HS. 1998. Isolation and Biological Characteristics of Vibrio harveyi Affecting Hatchery-related Penaeus Chinensis Larvae. Oceanologia et Limnologia Sinica 29:353361. (In Chinese with English abstract) 
473

474

475

476

477

478

479

480

481

482

483

484

485

486

487

488

489

490

491

492

493

494

495

496

497

498

499

500

501

502

503

504

505

506

507

508

509

510

511

512

513

514

515
Liu PC, and Lee KK. 1999. Cysteine protease is a major exotoxin of pathogenic luminous Vibrio harveyi in the tiger prawn, Penaeus monodon. Letters in Applied Microbiology 28:428430. DOI: 10.1046/j.1365-2672.1999.00555.x.

Liuxy PC, Lee KK, and Chen SN. 1996. Pathogenicity of different isolates of Vibrio harveyi in tiger prawn, Penaeus monodon. Letters in Applied Microbiology 22:413-416. DOI: 10.1111/j.1472-765X.1996.tb01192.x.

Massouras A, Hens K, Gubelmann C, Uplekar S, Decouttere F, Rougemont J, Cole ST, and Deplancke B. 2010. Primer-initiated sequence synthesis to detect and assemble structural variants. Nature Methods 7:485-486. DOI:10.1038/nmeth.f.308.

Mbengue M, Lo FT, Diallo AA, Ndiaye YS, Diouf M, and Ndiaye M. 2016. Pan-genome analysis of Senegalese and Gambian strains of Bacillus anthracis. African Journal of Biotechnology 15:2538-2546. DOI: 10.5897/ajb2016.14902.

Natrah FM, Ruwandeepika HA, Pawar S, Karunasagar I, Sorgeloos P, Bossier P, and Defoirdt T. 2011. Regulation of virulence factors by quorum sensing in Vibrio harveyi. Vet Microbiol 154:124-129. DOI: 10.1016/j.vetmic.2011.06.024.

Oakey HJ, and Owens L. 2000. A new bacteriophage, VHML, isolated from a toxin-producing strain of Vibrio harveyi in tropical Australia. Journal of Applied Microbiology 89:702709. DOI: 10.1046/j.1365-2672.2000.01169.x.

Owens L, Austin DA, and Austin B. 1996. Effect of strain origin on siderophore production in Vibrio harveyi isolates. Diseases of Aquatic Organisms 27:157-160. DOI: 10.3354/dao027157.

Prasad S, Morris PC, Hansen R, Meaden PG, and Austin B. 2005. A novel bacteriocin-like substance (BLIS) from a pathogenic strain of Vibrio harveyi. Microbiology 151:30513058. DOI: 10.1099/mic.0.28011-0.

Paradis E, Claude J, and Strimmer K. 2004. APE: Analyses of Phylogenetics and Evolution in R language. Bioinformatics 20:289-290. DOI: 10.1093/bioinformatics/btg412.

Pedersen K, Gram L, Austin DA, and Austin B. 1997. Pathogenicity of Vibrio anguillarum serogroup O1 strains compared to plasmids, outer membrane protein profiles and siderophore production. Journal of Applied Microbiology 82:365-371. DOI: 10.1046/j.1365-2672.1997.00373.x.

Pujalte MJ, Sitjà-Bobadilla A, Macián MC, Belloch C, Álvarez-Pellitero P, Pérez-Sánchez J, Uruburu F, and Garay E. 2003. Virulence and Molecular Typing of Vibrio harveyi Strains Isolated from Cultured Dentex, Gilthead Sea Bream and European Sea Bass. Systematic and Applied Microbiology 26:284-292. DOI: 10.1078/072320203322346146.

Ratledge C, and Dover LG. 2003. Iron Metabolism in Pathogenic Bacteria. Annual Review of Microbiology 54:881-941. DOI 10.1146/annurev.micro.54.1.881.

Ruwandeepika HAD, Jayaweera TSP, Bhowmick PP, Karunasagar I, Bossier P, and Defoirdt T. 2012. Pathogenesis, virulence factors and virulence regulation of vibrios belonging to the Harveyi clade. Reviews in Aquaculture 4:59-74. DOI: 10.1111/j.1753-5131.2012.01061.x.

Sawabe T, Kitatsukamoto K, and Thompson FL. 2007. Inferring the Evolutionary History of Vibrios by Means of Multilocus Sequence Analysis. Journal of Bacteriology 189:79327936. DOI: 10.1128/JB.00693-07.

Schikorski D, Renault T, Paillard C, Bidaulttoffin A, Tourbiez D, and Saulnier D. 2013. 
516

517

518

519

520

521

522

523

524

525

526

527

528

529

530

531

532

533

534

535

536

537

538

539

540

541

542

543

544

545

546

547

548

549

550

551

552

553

554

555

556

557

558
Development of TaqMan real-time PCR assays for monitoring Vibrio harveyi infection and a plasmid harbored by virulent strains in European abalone Haliotis tuberculata aquaculture. Aquaculture 392:106-112. DOI: 10.1016/j.aquaculture.2013.02.005.

Seemann T. 2014. Prokka: rapid prokaryotic genome annotation. Bioinformatics 30:2068-2069. DOI: 10.1093/bioinformatics/btu153.

Soto-Rodriguez SA, Roque A, Lizarraga-Partida ML, Guerra-Flores AL, and Gomez-Gil B. 2003. Virulence of luminous vibrios to Artemia franciscana nauplii. Diseases Aquatic Organnisms 53:231-240. DOI: 10.3354/dao053231.

Teo JWP, Tan TMC, and Poh CL. 2002. Genetic determinants of tetracycline resistance in Vibrio harveyi. Antimicrobial Agents and Chemotherapy 46:1038-1045. DOI: 10.1128/AAC.46.4.1038-1045.2002.

Teo JWP, Zhang L-H, and Poh CL. 2003. Cloning and characterization of a novel lipase from Vibrio harveyi strain AP6. Gene 312:181-188. DOI: 10.1016/S0378-1119(03)00615-2.

Unterweger D, Miyata ST, Bachmann V, Brooks T, Mullins T, Kostiuk B, Provenzano D, and Pukatzki S. 2014. The Vibrio cholerae type VI secretion system employs diverse effector modules for intraspecific competition. Nature Communications 5:3549-3549. DOI: 10.1038/ncomms4549.

Wang Z, IV WJH, Kim S, Lin B, and Voraa GJ. 2014. Complete Genome Sequence of the Bioluminescent Marine Bacterium Vibrio harveyi ATCC 33843 (392 [MAV]). Genome announcements 3:e01493-01414. DOI: 10.1128/genomeA.01493-14.

Won KM, and Park SI. 2008. Pathogenicity of Vibrio harveyi to cultured marine fishes in Korea. Aquaculture 285:8-13. DOI: 10.1016/j.aquaculture.2008.08.013.

Zhang X, and Austin B. 2000. Pathogenicity of Vibrio harveyi to salmonids. Journal of Fish Diseases 23:93-102. DOI: 10.1046/j.1365-2761.2000.00214.x.

Zhang XZ, Wen WJ, Feng YQ, Xie ZY, and Zhou YC. 2010. Isolation, identification and antibiotic sensitivity analysis of bacterial pathogen from proboscis intumescence disease in Babylonia areolata. Marine Sciences 34:7-12. (In Chinese with English abstract)

Zorrilla I, Arijo S, Chabrillon M, Diaz P, Martinezmanzanares E, Balebona MC, and Morinigo MA. 2003. Vibrio species isolated from diseased farmed sole, Solea senegalensis (Kaup), and evaluation of the potential virulence role of their extracellular products. Journal of Fish Diseases 26:103-108. DOI: 10.1046/j.1365-2761.2003.00437.x.

Zoued A, Brunet YR, Durand E, Aschtgen M, Logger L, Douzi B, Journet L, Cambillau C, and Cascales E. 2014. Architecture and assembly of the Type VI secretion system. Biochimica et Biophysica Acta 1843:1664-1673. DOI: 10.1016/j.bbamcr.2014.03.018. 
559

560

561

562

563

564

565

566

567

568

569

570

571

572

573

574 
Table $\mathbf{1}$ (on next page)

Comparison of the chromosomal properties of $V$. harveyi QT520, ATCC 33843 (392 [MAV]) and ATCC 43516. 
1 Table 1 Comparison of the chromosomal properties of $V$. harveyi QT520, ATCC 33843 (392

2 [MAV]) and ATCC 43516.

\begin{tabular}{cccc}
\hline Strain & QT520 & $\begin{array}{c}\text { ATCC 33843 } \\
(392[\mathrm{MAV}])\end{array}$ & ATCC 43516 \\
\hline Genome size(bp) & 6070846 & 5881490 & 6038881 \\
GC content & $45 \%$ & $44.96 \%$ & $44.90 \%$ \\
Open reading frames & 5701 & 5393 & 5479 \\
Average length(bp) & 925 & - & - \\
\% of ecoded gene & 96.19 & 95.18 & 95.80 \\
Annotated genes & 4080 & - & - \\
Hypothetical proteins & 1497 & 825 & - \\
tRNA & 134 & 131 & 37 \\
rRNA & 37 & 38 & 98.44 \\
Average nucleotide identity & 100.00 & 98.33 & CP014038.1 \\
& CP018680,CP018681 & & CP014039.1 \\
GeneBank Accession No. & CP018682,CP018683 & CP009467.2,CP009468.1 & \\
& CP018684 & & \\
\hline
\end{tabular}

3 
Table 2 (on next page)

The quantity of TnSS gene in the genome sequences of QT520, ATCC 33843 (392 [MAV]) and ATCC 43516. 
1

2 Table 2 The quantity of TnSS gene in the genome sequences of QT520, ATCC 33843 (392

3 [MAV]) and ATCC 43516.

\begin{tabular}{cccccc}
\hline Strain & \multicolumn{5}{c}{ TnSS } \\
\hline QT520 & 5 & II & III & IV & VI \\
ATCC & 28 & 32 & 21 & 45 \\
$\begin{array}{c}33843(392 \\
\text { [MAV]) }\end{array}$ & 0 & 7 & 12 & 4 & 0 \\
ATCC & 0 & 7 & 14 & 4 & 0 \\
43516 & & & & \\
\hline
\end{tabular}

4

5

6 
Table 3 (on next page)

Artificial infection results of the strain QT520. 
1

2 Table 3 Artificial infection results of the strain QT520.

\begin{tabular}{|c|c|c|c|c|c|c|c|c|c|c|c|}
\hline \multirow{2}{*}{ group } & \multirow{2}{*}{$\begin{array}{c}\text { Concentratio } \\
\text { n of QT520 } \\
(\mathrm{CFU} / \mathrm{mL}) \\
\end{array}$} & \multirow{2}{*}{$\begin{array}{c}\text { Numbe } \\
\quad \mathbf{r}\end{array}$} & \multicolumn{7}{|c|}{ Accumulative death number } & \multirow{2}{*}{$\begin{array}{c}\text { Total } \\
\text { death } \\
\mathbf{s} \\
\end{array}$} & \multirow{2}{*}{$\begin{array}{c}\text { Mortali } \\
\mathbf{y} \\
(\%) \\
\end{array}$} \\
\hline & & & 1 & 2 & 3 & 4 & 5 & 6 & 7 & & \\
\hline 1 & $1.47 \times 10^{8}$ & 10 & 9 & 1 & 0 & 0 & 0 & 0 & 0 & 10 & 100 \\
\hline 2 & $1.47 \times 10^{7}$ & 10 & 6 & 2 & 0 & 0 & 0 & 0 & 0 & 8 & 80 \\
\hline 3 & $1.47 \times 10^{6}$ & 10 & 0 & 4 & 0 & 0 & 0 & 0 & 0 & 4 & 40 \\
\hline 4 & $1.47 \times 10^{5}$ & 10 & 0 & 0 & 0 & 0 & 0 & 0 & 0 & 0 & 0 \\
\hline Control & $0.8 \% \mathrm{NaCl}$ & 10 & 0 & 0 & 0 & 0 & 0 & 0 & 0 & 0 & 0 \\
\hline
\end{tabular}

3

4 
Figure 1

Electron micrograph.

The electron micrograph of bacterium QT520( $\left({ }_{6000)}\right.$.

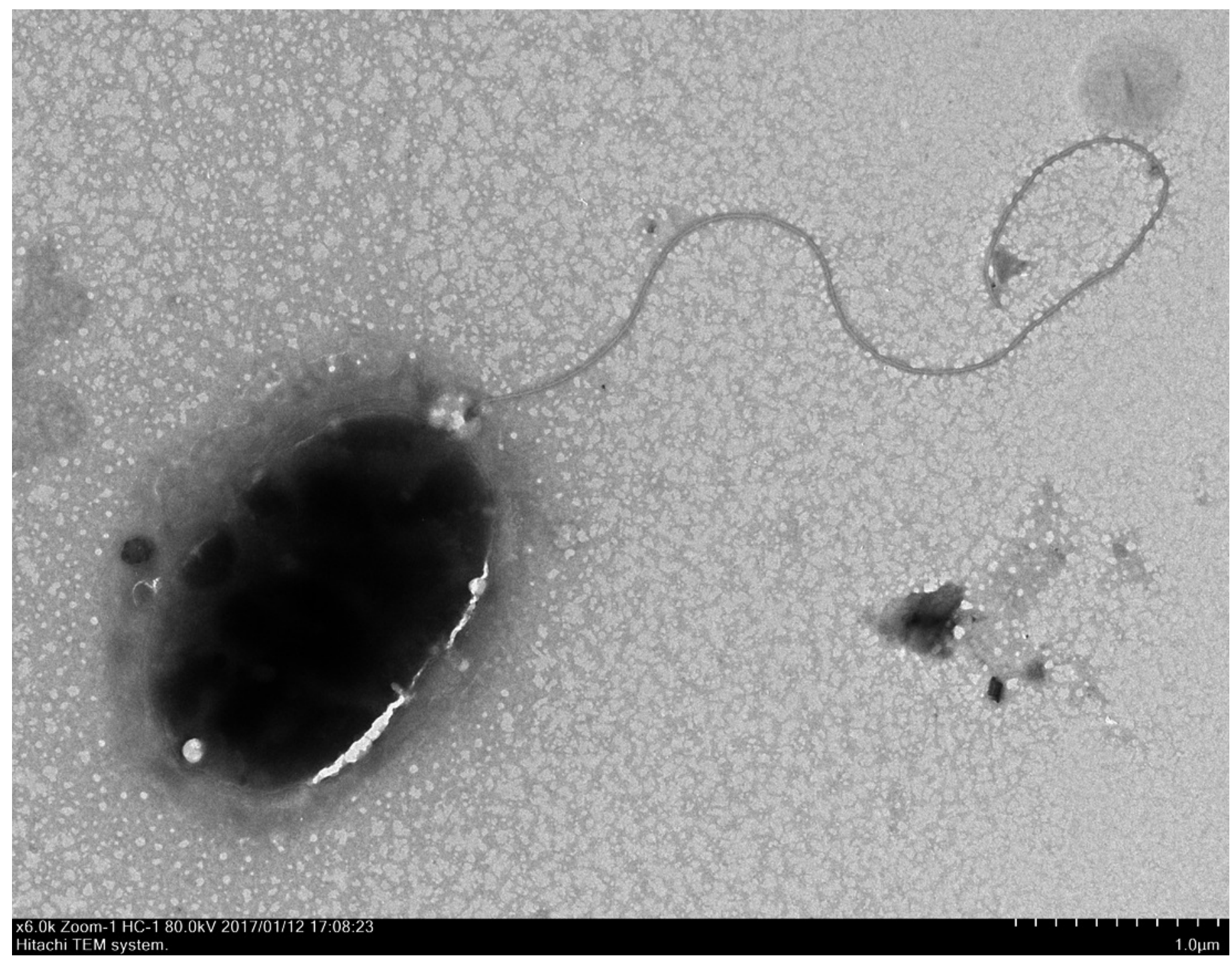


Figure 2

Genome map of V. harveyi QT520.

Chromosome I (A) and Chromosome II (B) Plasmid p1 (C), p2 (D) and p3 (E). The outer circle indicates the location of all annotated ORFs, and all of them are colored differently according to the COG assignments. The middle circle with black peaks indicates GC content. The inner circle indicates GC-skew (green: GC-skew+; purple: GC-skew-) .

A

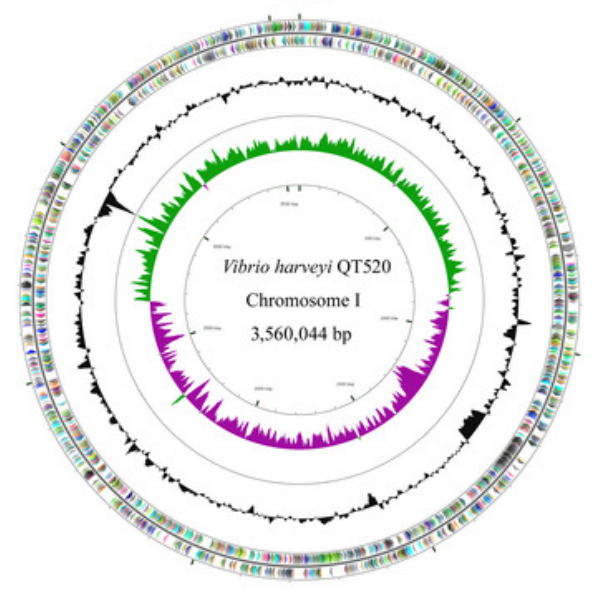

$\mathrm{C}$
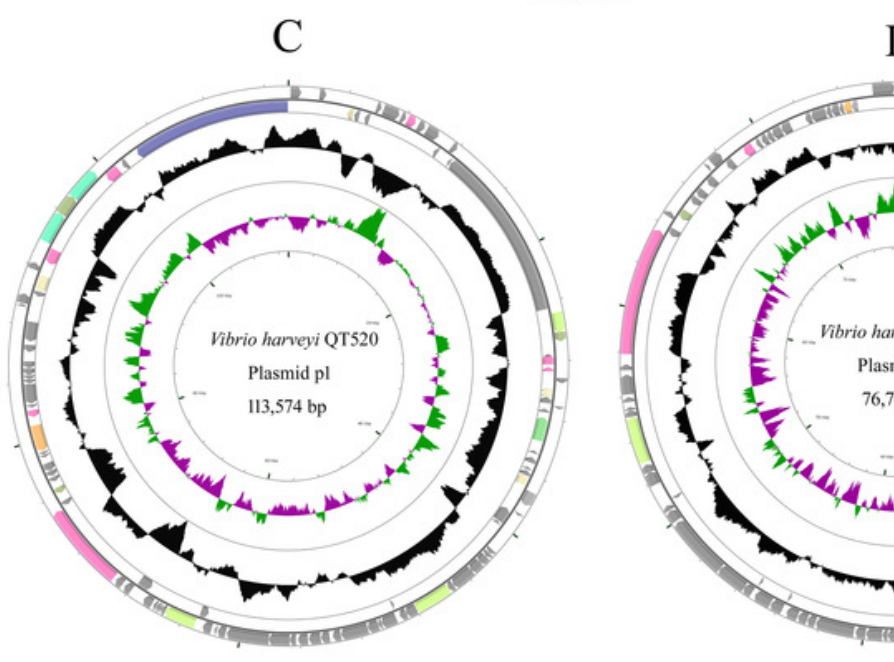

$\mathrm{B}$
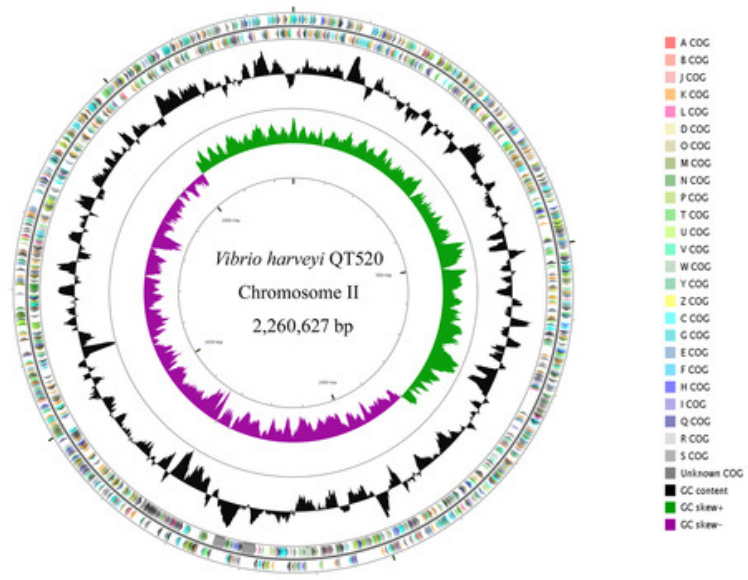

D
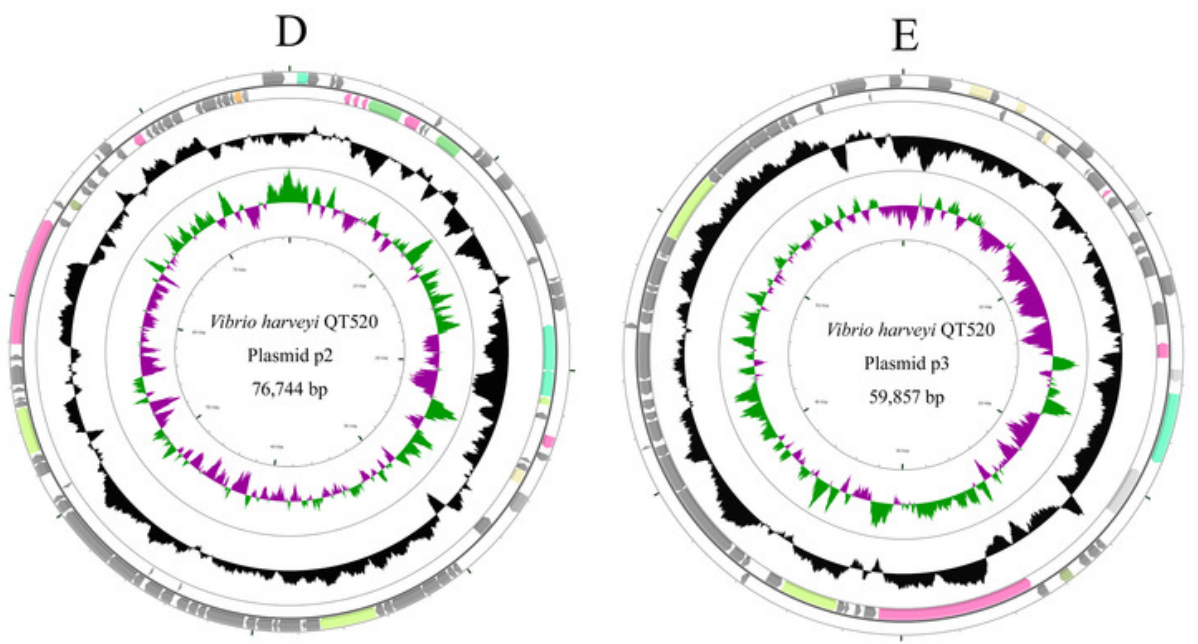


\section{Figure 3}

\section{COG databases.}

\section{Functional categorization of all predicted ORFs in the genome of QT520 based on COG}

\section{databases.}

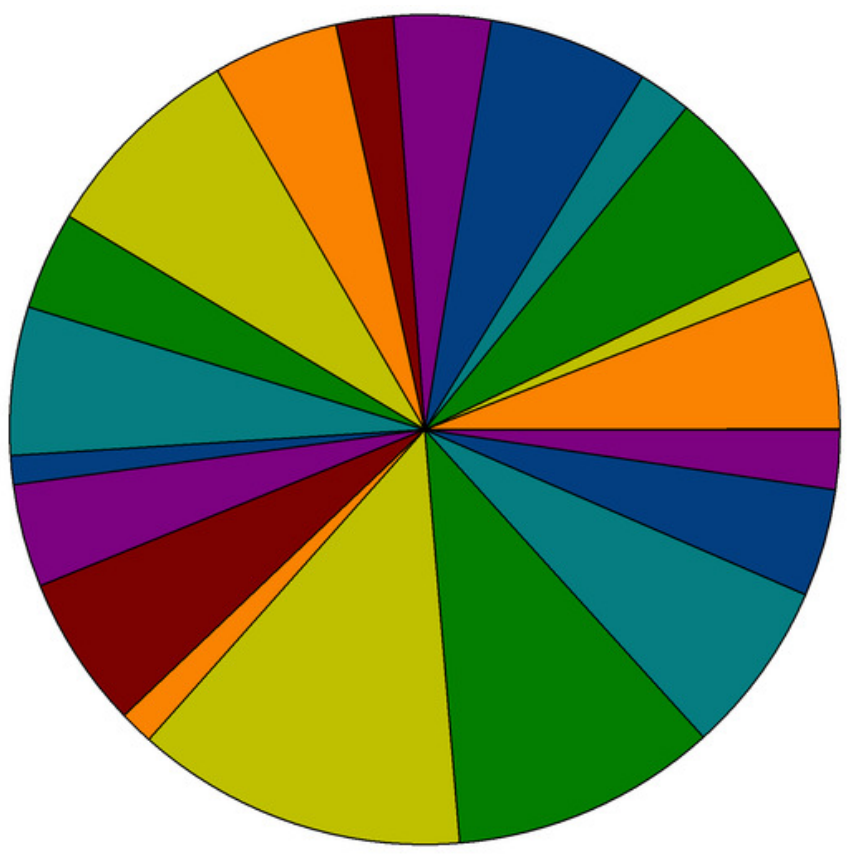

A RNA processing and modification (1)

C Energy production and conversion (241)

D Cell cycle control, cell division, chromosome partitioning (48)

E Amino acid transport and metabolism (287)

F Nucleotide transport and metabolism (84)

G Carbohydrate transport and metabolism (254)

H Coenzyme transport and metabolism (154)

I Lipid transport and metabolism (91)

J Translation, ribosomal structure and biogenesis (200)

K Transcription (329)

L Replication, recombination and repair (156)

M Cell wall/membrane/envelope biogenesis (236)

$\mathrm{N}$ Cell motility (46)

O Posttranslational modification, protein turnover, chaperones (164)

$P$ Inorganic ion transport and metabolism (243)

Q Secondary metabolites biosynthesis, transport and catabolism (54)

R General function prediction only (527)

S Function unknown (423)

T Signal transduction mechanisms (276)

U Intracellular trafficking, secretion, and vesicular transport (171)

$\checkmark$ Defense mechanisms (94)

W Extracellular structures (1) 


\section{Figure 4}

Phylogenetic tree analysis.

Phylogenetic tree analysis of 12 complete genome sequence of Vibrio sp. using ANI values

(A), core genes method (B). Phylogenetic tree analysis of Group I strains using MLST method

(C) and 16S rRNA sequence method (D).

A

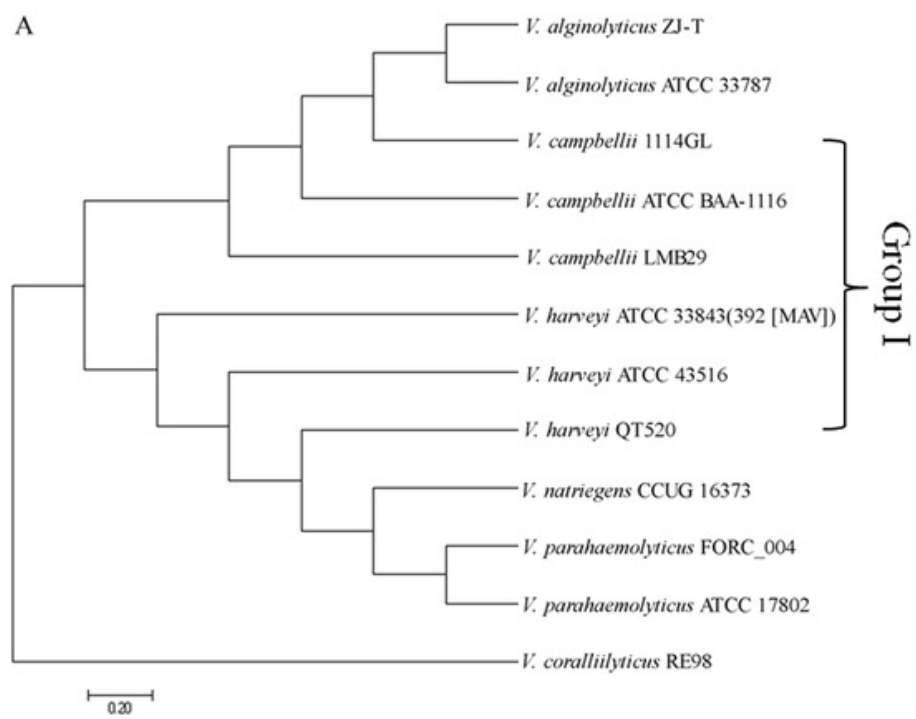

$\mathrm{C}$
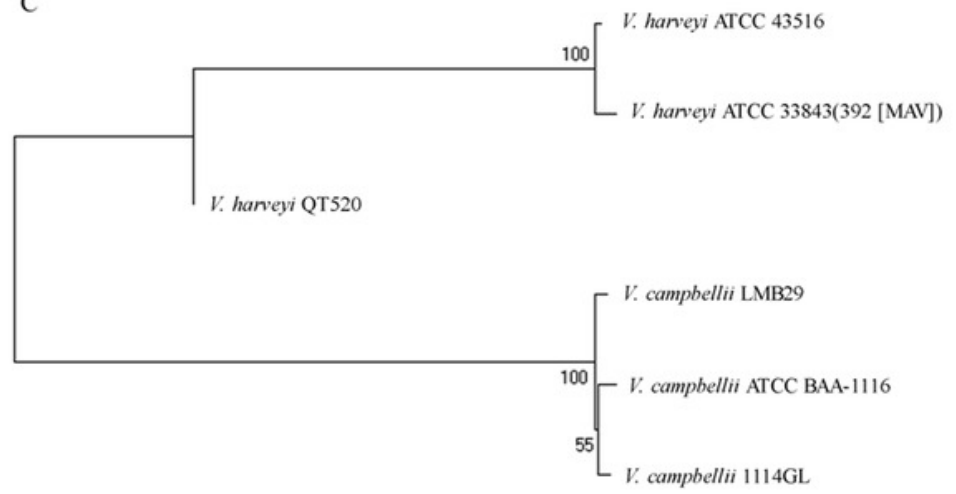

B
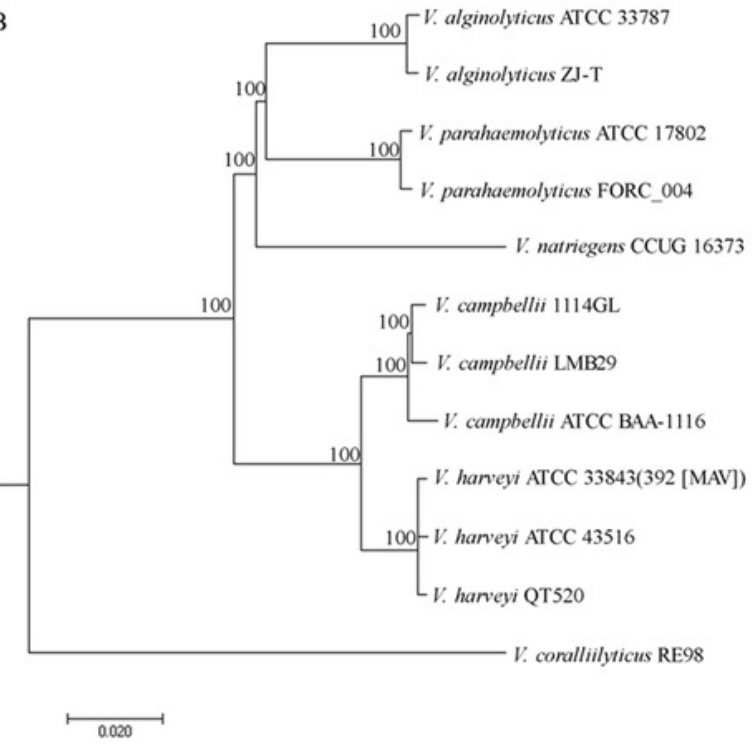

$\mathrm{D}$

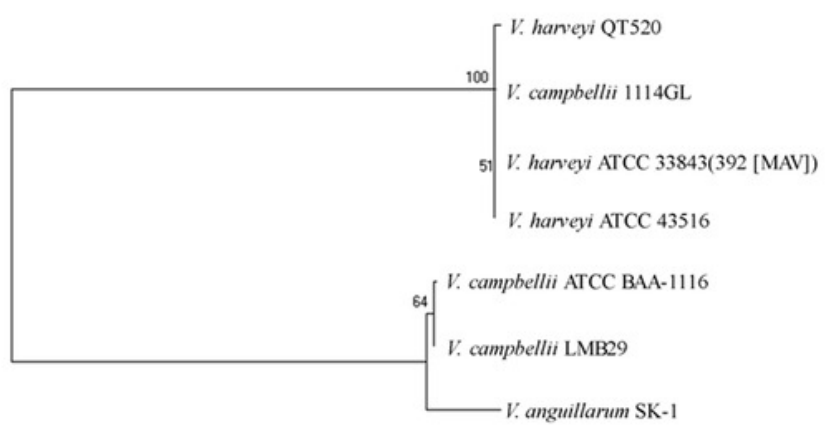




\section{Figure 5}

Mauve alignment of the genome.

Vibrio harveyi QT520 and genomes of ATCC 33843 (392 [MAV]) and ATCC 43516(A). The insertion region of QT520 compared with ATCC 33843 (392 [MAV]) (B). The insertion region of QT520 compared with ATCC 43516 (C). The collinear blocks of the same color represent the highly homologous regions. The genomes were drawn to scale based on the strain QT520 genome, showing one common insertion region in chromosome II of strain QT520 compared to genomes of ATCC 33843 (392 [MAV]) and ATCC 43516.

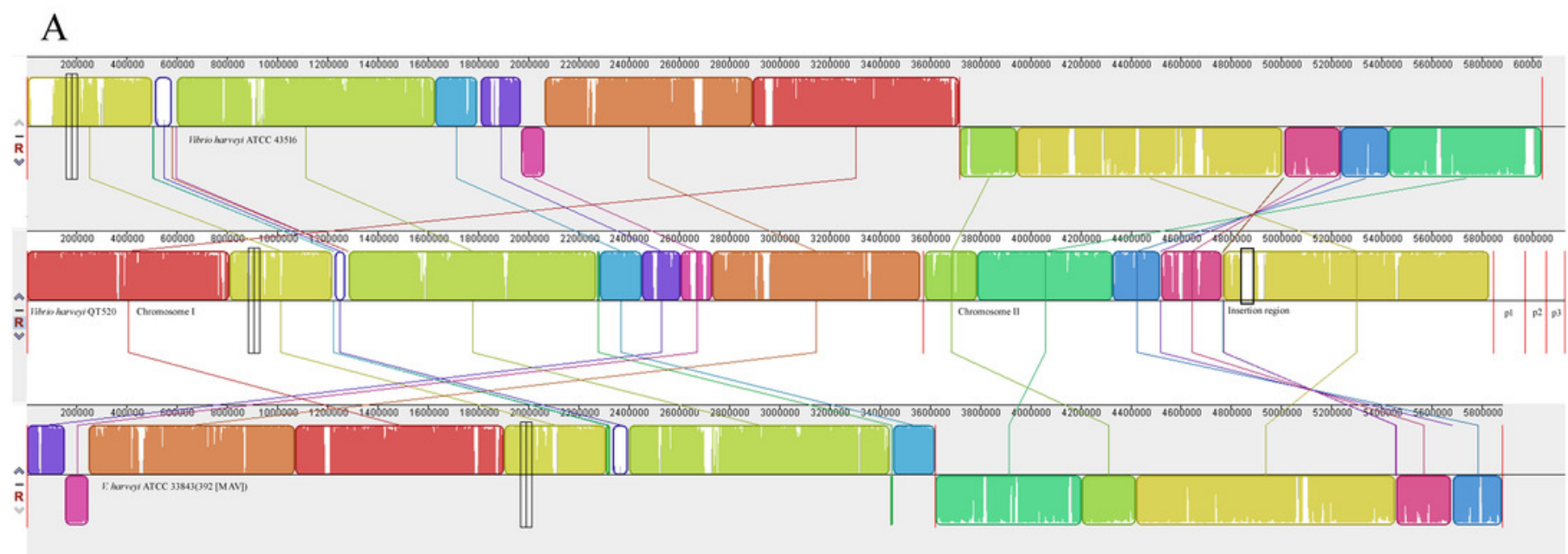

B

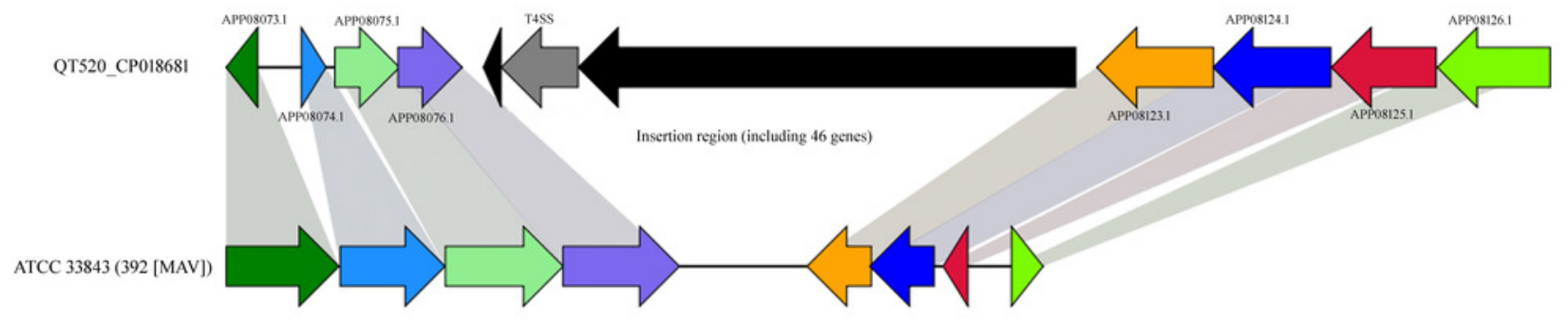

C

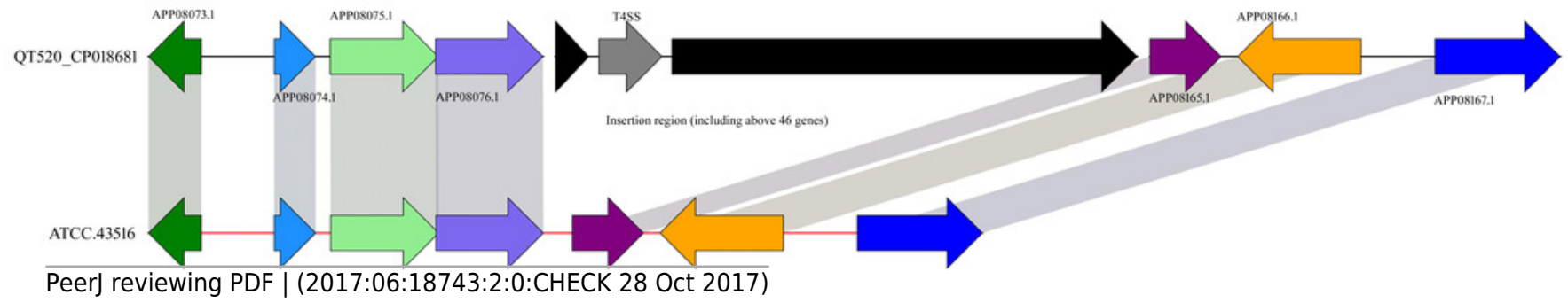

